Vol. 4, No. 1, 2018

Petro Hashchuk ${ }^{1}$, Roman Pelo ${ }^{2}$

${ }^{1}$ Department of Operation of Vehicle and Fire-rescue Techniques, Lviv State University of Life Safety, 35, Kleparivska Str., Lviv, Ukraine, E-mail: petroh@meta.ua

${ }^{2}$ Department of Operation and Repair of Automotive Vehicles, Lviv Polytechnic National University, 32, S. Bandera Str., Lviv, Ukraine, E-mail: Roman.A.Pelio@lpnu.ua

\title{
OPTIMAL GEAR SHIFT ALGORITHM IN THE CAR TRANSMISSION DURING ITS DECELERATION
}

Received: April 24, 2018 / Revised: June 23, 2018 / Accepted: June 26, 2018

(C) Hashchuk P., Pelo R., 2018

Abstract. On the way to improving the car one can not avoid the problem of optimal gear shift in stage transmissions. Typically, the gear (stage) shift laws are distinguished, which are optimal because of fuel efficiency, either in terms of dynamics (speed), or in terms of comfort I safety of the car, etc. And all these types of laws are considered to be special, irreducible to each other. Because of this, in the designs of real automotive transmissions, it is often foreseen for the driver to have several automatic control programs at the same time. But everything that is entrusted to the driver is to some extent the subjective negation of automaticity and optimality.

The purpose of the work is to refute such very common system of views on the optimality of transmission control as: it turns out there is a single optimal gear shift law, within which there are no contradictions, at least between energy efficiency requirements and the requirements for the dynamics (or performance) of the vehicle.

The basis of the research methodology is the fully motivated principle of non-interference of the automatic transmission control system in the choice of the car movement program - a choice that is largely due to the circumstances and road conditions of the vehicle movement. So, optimizing the gear shift laws, it is necessary to consider the movement program to be predetermined (subject only to the driver), and the consequences of forced deviation from it during the operation of the elements of transmission control should be minimized. Specifically, gear shifting is considered during the car deceleration.

Direct involvement of the engine in the process of gear changes is envisaged, that is, the implementation of the principle of active synchronization of the rotation speed of separate parts of the transmission on adjacent gears during their shifting. In this case, the transmission of mechanical energy through the transmission is carried out by a continuous flow. The implementation of the dynamic principles of automation also leads to a decrease in the amount of mechanical energy that is transformed into heat during the skid of gear shift elements (frictions, for example). This makes it possible to increase the durability of the gear-shift elements or to impose lighter requirements in the process of designing the transmission.

The described algorithm of the optimal transmission control of the car provides grounds for the formation of motivated guidelines for selecting the moments of gear shift also during purely manual control of the car. The obtained results are quite general, although significant simplifications were introduced into the car model. In particular, the scheme of the gearbox, considered to be very simple, actually fully reproduces the principles of work of the mechanical stage transmission of any structure. The process of gear shifting is so fast that the linearized reproduction of the operating modes of the "engine-transmission" system is quite natural and such that it can not distort the idea of the optimal functioning of the engine-transmission system.

Keywords: car, deceleration, stage transmission, gear shift law, fuel consumption, dynamics of movement. 


\section{Introduction}

Among the means of improving the car, automation of the compatible work of the internal combustion engine and transmission are of special importance. And it's not so important to facilitate the driver's work by automation, as to provide the car with the properties that significantly improve the efficiency of its work. So far, the problem of synthesizing the optimal gear shift laws in stage transmissions, which by many indicators are considerably inferior to those without stages, is still unresolved. There is still no general consistent concept of optimality.

The interpretation of optimality when there are no conflicts between the requirements for increasing the dynamism and productivity of the car, minimizing the energy costs and negative environmental impact and ensuring a special level of comfort of the vehicle use, etc., is considered to be relevant. To a large extent this can be reached.

\section{Problem Statement}

Typically, the laws of gear (stage) shift in the car transmission are distinguished, which are optimal because of fuel efficiency, either in terms of dynamics (speed), or in terms of comfort / safety of the car, etc. And all these types of laws are considered to be special, irreducible to each other. Because of this, in the designs of real automotive transmissions, it is often foreseen for the driver to have several automatic control programs at the same time. But everything that is entrusted to the driver is to some extent the subjective negation of automaticity and optimality as such.

So there is a need to find out if really different requirements for automatic systems are fundamentally contradictory, or contradictions are only a consequence of inadequate understanding of the optimality of transmission properties. It is especially interesting to pay attention to the stages shifting in the transmission during the deceleration of the car. They are usually treated too simplified.

\section{Review of Information Sources}

At the end of 1965, the test laboratory of the Engine and Foundry Products branch of the Ford Motor Company was given a task to reproduce at the simulation test stand the conditions of the car work during a 24 hour Le Mans race. The purpose of the work was by means of simulation to objectively compare two variants of transmission of the Mark II GT car in conditions that are as close to the real as possible. So the test objects were the Mark II car with a 7,000 $\mathrm{cm}^{3}$ engine, equipped with a standard four-stage gearbox and the main transmission, and as if the same J-car with the same engine, but equipped with a two-stage automatic transmission [1]. Both gearboxes are Ford's developments.

To test a standard four-stage gearbox in the stand conditions, the Mark II Programmer was developed. Based on the information gathered by the laboratory, the experimenters came to the conclusion that the moments of gear shifting $k \rightarrow n$ (from $-k$ to $-n$ ) should be set primitively by such constant frequencies of engine shaft rotation, $\min ^{-1}: 1 \rightarrow 2-6800 ; 2 \rightarrow 3-6800 ; 3 \rightarrow 4-6200 ; 4 \rightarrow 3-5040$; $4 \rightarrow 2-3900 ; 3 \rightarrow 2-3900 ; 2 \rightarrow 1-2600$. Duration of shifting $-0.3-0.7 \mathrm{~s}$.

Thus, the acting layout-analog of the system of automatic gear shift of the mechanical stage transmission was created. The gear shift laws in this transmission are largely a primitive imitation of the driver's actions that can hardly be considered faultless.

But most of all, in the process of improving the car, attention was paid to the laws of management of socalled automatic stage transmissions. Automatic is usually referred to as gearbox with hydrodynamic couplings or transformers. In the common automatic gearbox, oil is the medium, which transmits energy in a hydrodynamic transmission, serves as a carrier of signals in the control system and the working body in the elements of stages switching on and off, works as a lubricant and diverts heat. The automatic gearbox control system regulates the working pressure, sets the gear-shift law and performs some auxiliary functions.

Conditions of shifting/ switching from one transmission to another in different gearboxes are different. However, until some time, some general tendencies towards the formation of gear shift conditions were formed [2]. 
For example, if the driver installs a small fuel feed into the engine, for the automaton this means that the driver does not intend to move with much acceleration. Therefore, the automation shifts to a higher gear at a low speed and thereby contributes to the fuel economy. In the case of full fuel supply, automatic shifting to a higher stage occurs at higher frequencies of the engine shaft rotation. In order to reduce noise on lower gears, the frequency of the engine shaft rotation is limited. All automatic gearboxes are shifted up until fuel supply decreases, i.e. when the movement conditions start to contradict the law of gear shifting. Once it was considered that due to the fact that there is no automatic gear-shift program suitable for all conditions of movement, manual shifting of stages is foreseen. Now this sentence is unacceptable.

Automatic shifting from the higher stage to the lower one was usually carried out regardless of the position of the fuel injection pedal in the event of a decrease in the speed of the vehicle. This was necessary in order to eliminate the harmful so-called cyclical shifting/switching. To intensify the acceleration it may be necessary to shift to a lower stage when the fuel injection pedal is pressed to the maximum feed injection position. This mode was named Kick down (in the USA).

Thus, there was an understanding that automation should try to guess the driver's desire and not discourage him.

Usually the gear shift program is set with the view of ensuring optimal dynamics of acceleration (without extensive "rotation" of the engine). The shift depends on the vehicle's speed and position of the oil supply pedal (as in Daimler-Benz automated gear). During the shift of stages without disruption of hauling capacity the friction of elements generate heat. As a result of limitation of friction elements size the time of their slip under the full load should not exceed $1 \mathrm{~s}$. When the duration of shift is short there are usually some thrusts. The operating system regulates the turn-on time of the shift with full load of engine within $0.5-0.7 \mathrm{~s}$ limits.

It is worth mentioning that Toyota used to equip their engines Corona, Corolla, Carina, 1800 i 2000 only with an A 40 automated gear box [3]. The distinguishing feature of the gear box is the absence of band brake and the application of multidisc friction muffs and overrunning clutches. Its main elements are the following - hydrodynamic transformer, three-stage planetary gear reduction with two planetary gear sets and a control unit. The usage of the gear stages were determined depending on accelerator position $h$ and the vehicle's speed $V$ (the frequency $n_{k v}$ of cardan axle rotation), Fig. 1: $u$ - transmission ratio of back-axle reducer; $1 \rightarrow 2$ and $2 \rightarrow 1$ - direct gear shift from low to the second gear and reverse from the second to low gear; $2 \rightarrow 3$ and $3 \rightarrow 2$ - direct gear shift from the second to the third and reversed from the third to the second; $2 \rightarrow 1(\mathrm{~L})$ - the so called range $\mathrm{L} ; 3 \rightarrow 2(\mathrm{~L} \& \mathrm{Z})$ - ranges $\mathrm{L}$ and $\mathrm{Z}$. The diagram in the Fig. 1 exemplifies the conventional graphic of gear shift principles representation [4-6].

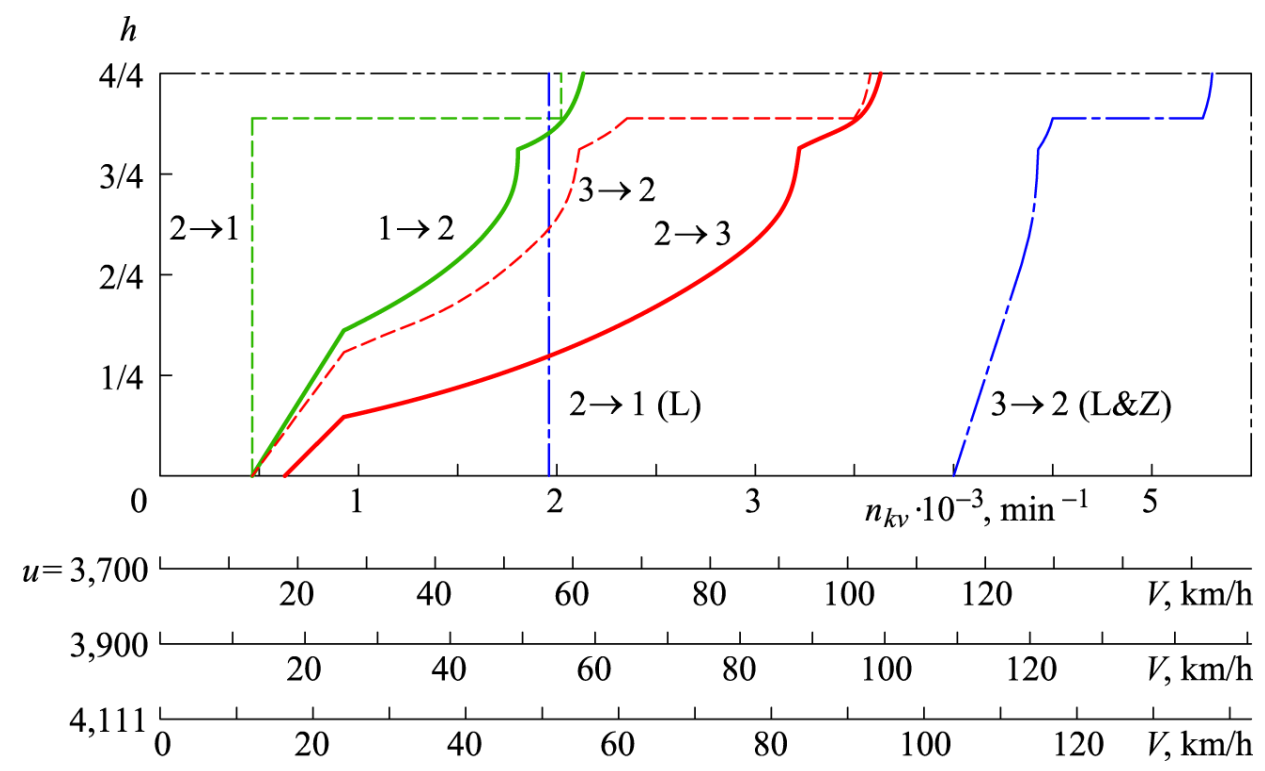

Fig. 1. Classical diagram of gear shift, graphically representing the laws of automobile stage transmission operation 
Then, the priority in automobile industry was given to energy preservation. Transmission, in particular, was considered as a means to realize those operating conditions of internal combustion engine which are characterized by minimal specific loss of fuel (maximal efficiency) on a set of different values of power $[7,8]$. In this way the equitable compromise between energy preservation and automobile efficiency was achieved. But there could be found numerous equitable compromises. Therefor the optimal laws of gear shift do not seem unambiguous in principle.

It was determined that the objective conception of optimal gear shift should unconditionally follow the principle according to which the intrusion of automated equipment into the driver's choice of operating vehicle is eliminated $[7,9,10]$. Thus the program of vehicle speed change is considered set. In this case the program $\omega_{a}=\omega_{a}(t)$ of angular velocity change $\omega_{a}$ rotation of transmission output shaft $(t-$ time) is considered set as well as the program load change (of rotation moment $M_{a}=M_{a}(t)$ ) at this shaft. Consequently, the problem of automobile dynamics intensification seems objectively eliminated - the choice of speed mode depends solely on the driver. Thus the optimization of gear shift laws should be defined based on the criterion of energy preservation and efficiency. This approach makes it possible to treat the laws of gear shift differently [11-13], unlike the chart in Fig. 1.

\section{Objectives of the Research}

The aim of the research is to disprove the widely spread system of views concerning the optimization of transmission operation: it is apparent that there is only one optimal law of gear shift, devoid of any contradictions, at least between the requirements of energy preservation and requirements of vehicle's dynamics, efficiency.

To perform the procedure of gear shift optimal laws synthesis one has to observe the gearbox parameters and fuel efficiency of the engine $Q_{t}=Q_{t}\left(M_{e}, \omega_{e}\right)$ [7, 11-13], in which $Q_{t}$ - propellant combustion rate, $M_{e}$ - rotation moment, $\omega_{e}$ - engine shaft rotation velocity. The peculiarities of formulation (synthesis) of optimal gear shift laws without power loss should be analyzed on the example of schematically simple stage mechanical gearbox with frictional operation means in case of realization of a set simple program of automobile's motion. Thus it is necessary to recreate in a set interval of time $t_{A}-t_{B}$ of $A B$ fragment of constant deceleration program $v=V(t)$ of automobile motion (Fig. 2), optimally shifting transmissions in the gearbox, schematically represented in Fig. 3.

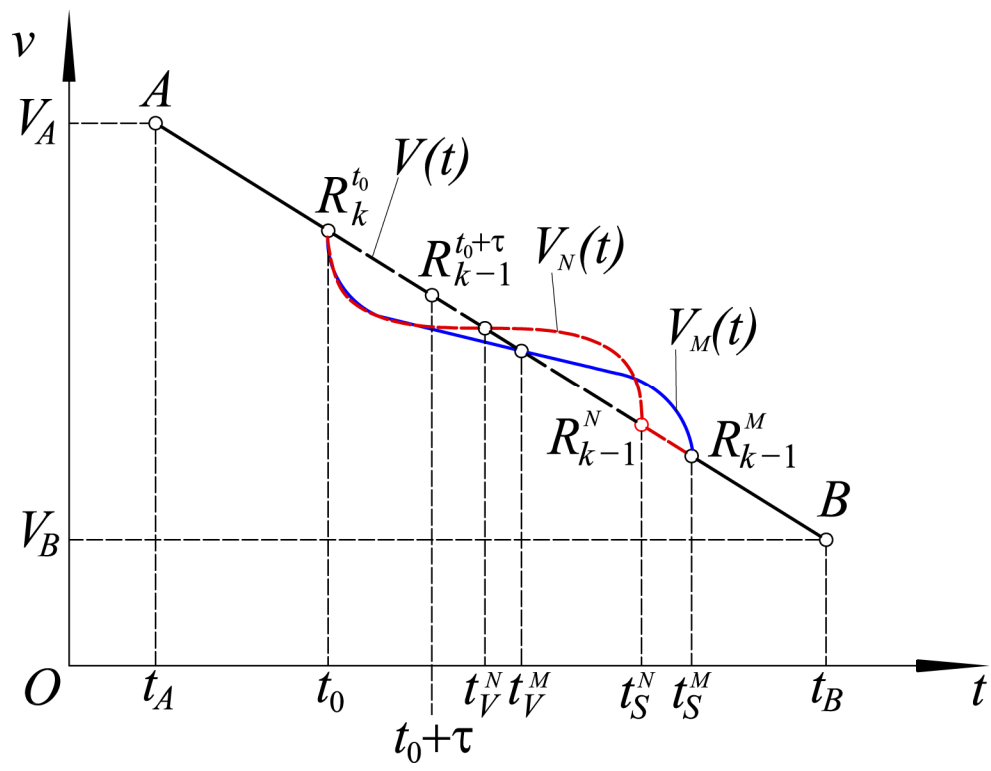

Fig. 2. The fragment of automobile's motion program 


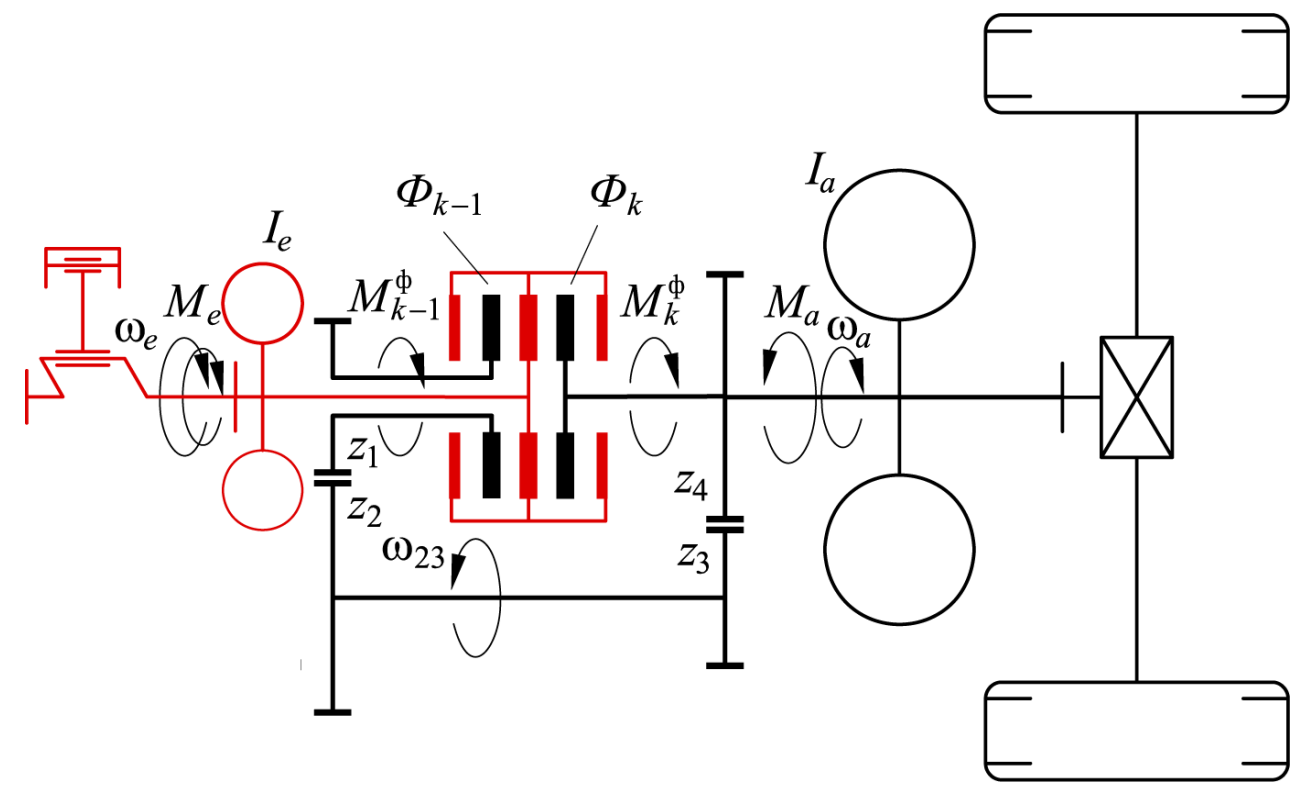

Fig. 3. The scheme of two stages combination in automobile transmission, one of which is direct transmission

Obviously that it is the driver who decides on the motion program according to the conditions of the motion. The automatic device cannot influence this choice. But the deviations, as the deviations $V_{*}=V_{N}(t)$ or $V_{*}=V_{M}(t)$, from the set program (see Fig. 2) are possible because of sheer technical limitations. But it is possible to introduce the requirement that at any moment $t_{*}=t_{S}^{*}$ (or $t_{S}^{*}=t_{S}^{M}$ ), (see Fig. 2) after the shift of transmissions the deviation in the program of motion cannot be found. It means that at that moment the following conditions are true

$$
v\left(t_{S}^{*}\right)=V_{*}\left(t_{S}^{*}\right)=V\left(t_{S}^{*}\right) \text { and } S=\int_{t_{0}}^{t_{S}^{*}} V_{*}(t) d t=\int_{t_{0}}^{t_{S}^{*}} V(t) d t .
$$

This fragment of vehicle's motion program completely or partially can be implemented, making the engine to operate at a set of modes $R$, represented by some curves $N_{e}=N_{e k}\left(\omega_{e}\right)$ or $N_{e}=N_{e(k-1)}\left(\omega_{e}\right)$ correspondingly at $k$ or $(k-1)$ transmissions (Fig. $4 N_{e}$ and $M_{e}$ are capacity and rotation moment of the engine). Within the system of coordinates $\omega_{e} O N_{e}$ lines $N_{e}=N_{e}^{+}\left(\omega_{e}\right), N_{e}=N_{e}^{-}\left(\omega_{e}\right), \omega_{e}=\omega_{e}^{+}=$const, $\omega_{e}=\omega_{e}^{-}=$const represent the so called external modes of engine operation. Let the modes $R_{k}^{t_{A}}$ and $R_{k-1}^{t_{B}}$ of engine operation belong to this set corresponding to the beginning $A$ and the end $B$ of the set automobile's motion program (to the moments $t_{A}$ and $t_{B}$, see Fig. 2). In this case the chosen motion program $v=V(t)$ can be realized, using obligatory two gears o transmission; the shift of gears from $k$ to $(k-1)$ should take place when the engine reach at a turned on $k$ transmission a certain mode on the line $N_{e k}\left(\omega_{e}\right)$, see Fig . 4.

Let the engine operation mode $R$ moving right along the curve $N_{e}=N_{e k}\left(\omega_{e}\right)$ (a certain gear $k$ is switched on) transforms into the mode $R_{k}^{t_{0}}$ and at the same moment the shift of gears $(k-1)$ is due to start. The upper symbol indicates the time of the vehicle's motion program which coincides with the start of gear shift; in particular, the $t_{0}$ symbol in $R_{k}^{t_{0}}$ indicates that the moment of gear shift start from $k$ to $(k-1)$ coincides with the moment $t_{0}$ on the motion program $v=V(t)$, see Fig. 2 . At this very moment $t_{0}$ the friction clutches $\Phi_{k}$ and $\Phi_{k-1}$ start to operate (see Fig. $3 ; I_{e}$ - moment of inertia of transmission masses connected with the gearbox input shaft; $I_{a}$ - moment of inertia of transmission masses connected 
with the gearbox output shaft) in such a way that after a certain fixed time $\tau$ of full $(k-1)$ gear turn-on the engine operation mode is to coincide with $R_{k-1}^{t_{0}+\tau}$ mode that belongs to a certain curve $N_{e}=N_{e(k-1)}\left(\omega_{e}\right)$. The figure of the lower index in $R_{k-1}^{t_{0}+\tau}$ indicates the number of the turned-on gear after the gear shift. The upper symbol indicated the $t=t_{0}+\tau$ moment of the end of the shift.

$$
\begin{gathered}
\text { M-control } \\
R_{k}^{t_{A}}-R_{k}^{t_{0}}-a-R_{k-1}^{t_{0}+\tau^{\prime}}-b-c-R_{k-1}^{M}-R_{k-1}^{t_{B}} \quad R_{k}^{t_{A}}-R_{k}^{t_{0}}-a-R_{k-1}^{t_{0}+\tau^{\prime \prime}}-b-R_{k-1}^{N}-R_{k-1}^{t_{B}}
\end{gathered}
$$

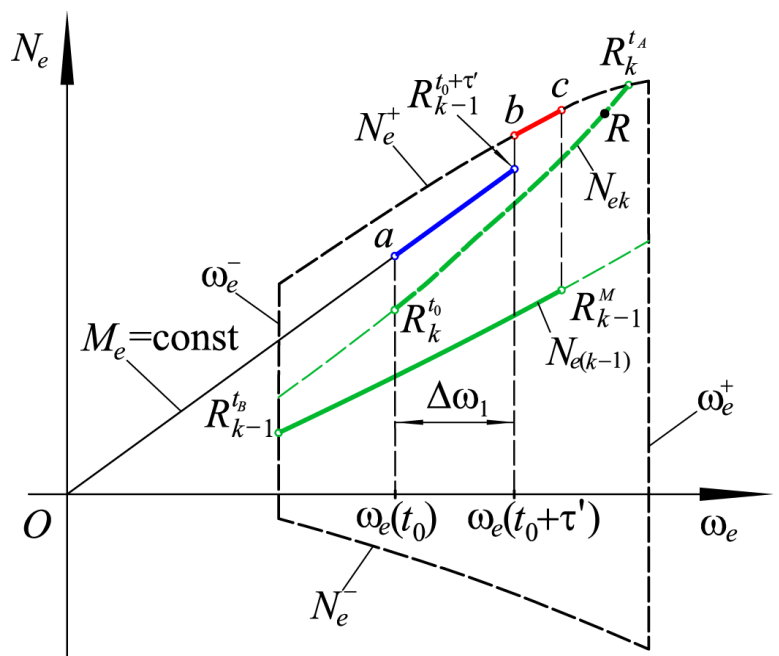

$a$

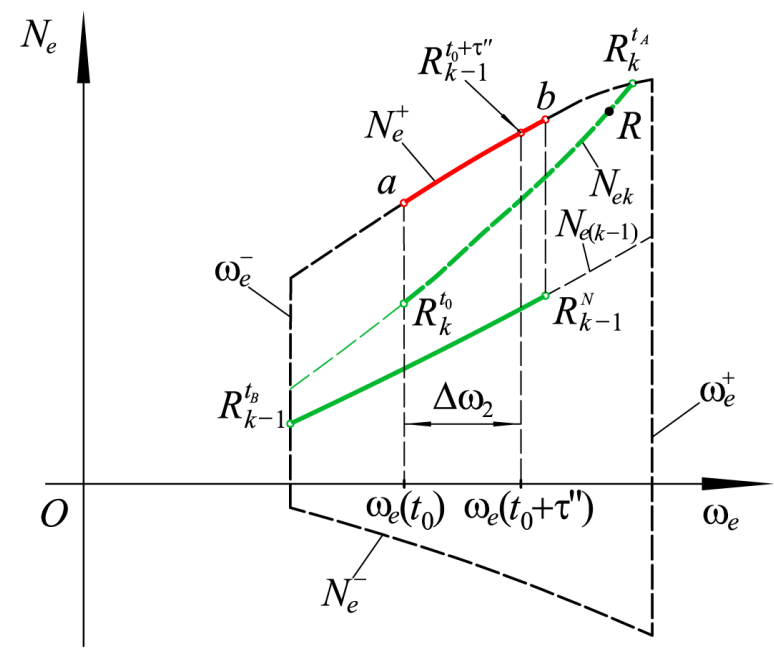

$b$

Fig. 4. Modes of engine operation at automobile's motion with constant deceleration when using M-control (a) and N-control (b)

The process of engine operation mode changes during time $\tau$ as a result of gear shift by friction clutches $\Phi_{k}$ and $\Phi_{k-1}$ depends on the selected way to control engine and friction clutches. As soon as the engine operation mode reaches the $R_{k-1}^{t_{0}+\tau}$ position the shift is completed and the following realization of the automobile's motion program will develop in such a way that the current mode $R$ will be moving along the curve $N_{e(k-1)}\left(\omega_{e}\right)$ up to a certain position $R_{k-1}^{t_{B}}$ which corresponds to the moment of automobile's motion program completion. Certainly, any other moment $t_{i}$ of the automobile's motion program can be treated as the moment $t_{0}$ of gear shift start (see Fig. 2), and instead of $t_{0}+\tau$ value that corresponds to the end of the friction clutches work one can operate with any other acceptable value $t_{i}+\tau$. The friction clutches $\Phi_{k}$ and $\Phi_{k-1}$ conjointly have to ensure the transition $R_{k}^{t_{i}}-R_{k-1}^{t_{i}+\tau_{j}}$ of engine operation mode $R$ form the curve $N_{e k}\left(\omega_{e}\right)$ to the curve $N_{e(k-1)}\left(\omega_{e}\right)$ without changes of a set automobile's motion program.

However this specific task can be performed applying different programs of friction clutches skidding. Monitoring the corresponding to the implemented program use of fuel we can set a problem about the energy saving laws of gear shift.

\section{Algorithm of Gear Shift}

According to the scheme represented in the Fig. 3

$$
M_{e}-I_{e} \frac{d \omega_{e}}{d t}=M_{k}^{\phi}+M_{k-1}^{\phi}=M_{k(k-1)}^{\phi}, M_{k}^{\phi}+\frac{M_{k-1}^{\phi}}{u_{k-1}}=M_{a},
$$


where $M_{k}^{\phi}$ and $M_{k-1}^{\phi}$ are rotation moments created by friction clutches $\Phi_{k}$ and $\Phi_{k-1} ; M_{k}^{\phi} \omega_{e} \geq 0$, $M_{k-1}^{\phi} \omega_{e} \geq 0 ; u_{k}-$ transmission ratio. As a vehicle's motion program is set, so at any moment the value is known (see the second equation (2))

$$
M_{k}^{\phi}(t)+\frac{M_{k-1}^{\phi}(t)}{u_{k-1}} \equiv M_{a}(t) .
$$

Let us consider the algorithm of synthesis of optimal laws of vehicle's mechanic stage transmission control without taking into consideration loss of energy caused by frictions in toothing and spindle bearing. Let allow the following

$$
M_{k}^{\phi}+M_{k-1}^{\phi}=M_{k(k-1)}^{\phi}(t)=-a t+b,
$$

where the coefficients $a$ and $b$ are determined by the values of $t_{i}, t_{i}+\tau_{j}$ parameters and the coordinates of points

$$
\left(M_{e k}^{t_{i}}-I_{e} \frac{d \omega_{e k}^{t_{i}}}{d t}, \omega_{e k}^{t_{i}}\right) \text { and }\left(M_{e(k-1)}^{t_{i}+\tau_{j}}-I_{e} \frac{d \omega_{e(k-1)}^{t_{i}+\tau_{j}}}{d t}, \omega_{e(k-1)}^{t_{i}+\tau_{j}}\right)
$$

respectively $\left(M_{e k}^{t_{i}}, \omega_{e k}^{t_{i}}\right.$ are coordinates of point $R_{k}^{t_{i}} ; M_{e(k-1)}^{t_{i}+\tau_{j}}, \omega_{e(k-1)}^{t_{i}+\tau_{j}}$ are coordinates of point $R_{k-1}^{t_{i}+\tau_{j}}$ ). The expression (3) specifically represents the program of two friction clutches joint work in the process of gear shift from $k$ to $(k-1)$ gears. As an example the Fig. 5 represents the shift of $\Phi_{k}$ and $\Phi_{k-1}$ friction clutches (see Fig. 3) in the form of programs of friction moments $M_{k}^{\phi}$ and $M_{k-1}^{\phi}$ changes in due course when the condition (3) is observed.

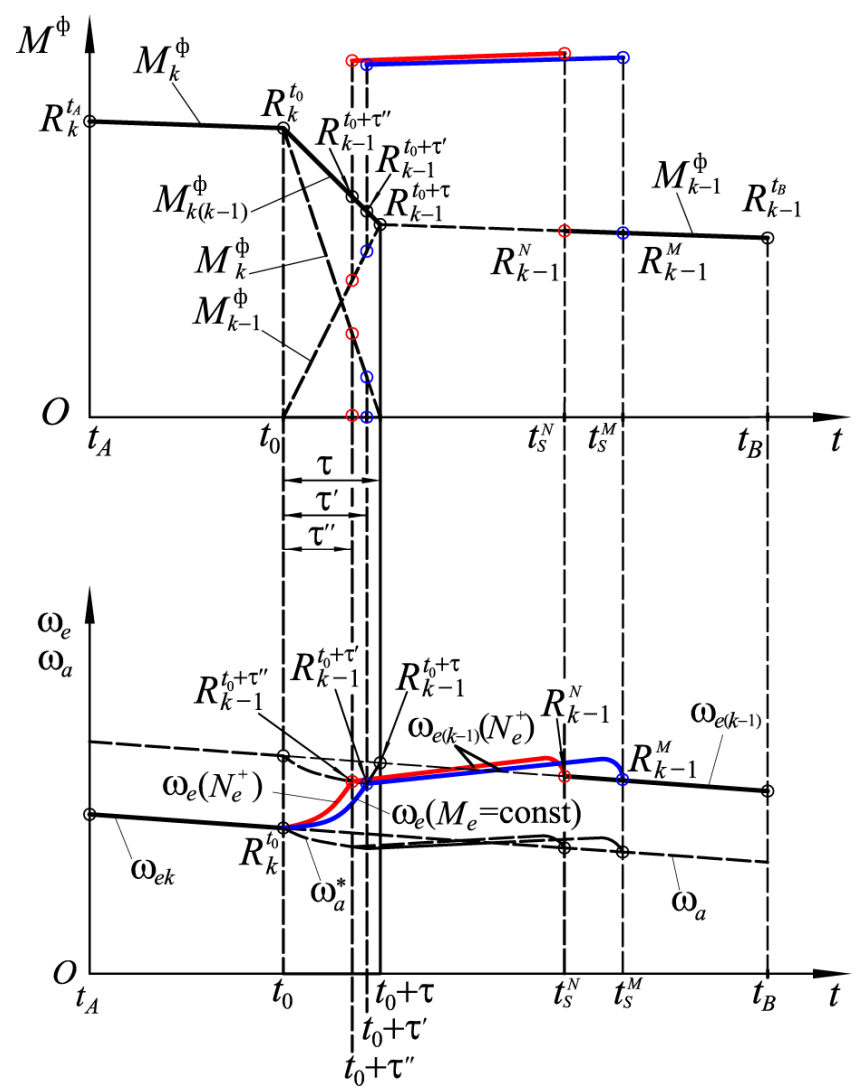

Fig. 5. The program of friction clutches shifts 
Thus, the correlations (2) and (3) jointly unambiguously determine the programs $M_{k}^{\phi}=M_{k}^{\phi}(t)$ and $M_{k-1}^{\phi}=M_{k-1}^{\phi}(t)$ of friction clutches $\Phi_{k}$ and $\Phi_{k-1}$ operation (through the parameters $a, b, u_{k}$, time $t$ and the known function $\left.M_{a}=M_{a}(t)\right)$ :

$$
M_{k}^{\phi}=\frac{M_{a}(t) u_{k-1}+a t-b}{u_{k-1}-1}, M_{k-1}^{\phi}=\frac{a t-b+M_{a}(t)}{u_{k-1}-1} .
$$

It is possible to reproduce the linear program $v=V(t)$ of automobile's deceleration within a time interval $t_{A}-t_{B}$ with the realization of the program (3) of friction clutches shift, in particular, if the engine operation mode $R$ moves within the system of coordinates $\omega_{e} O N_{e}$ along the line $R_{k}^{t_{A}}-R_{k}^{t_{0}}-a-R_{k-1}^{t_{0}+\tau^{\prime}}-b$ - $c-R_{k-1}^{M}-R_{k-1}^{t_{B}}$ (Fig. 4, a; let us recall, that the $R_{k}^{t_{A}}$ mode is to belong to the curve $N_{e}^{+}\left(\omega_{e}\right)$ and the $R_{k+1}^{t_{B}}$ mode - to the line $\omega_{e}^{-}$).

Herewith in the process of friction clutches operation (skidding) let the engine "be obliged" to realize the stable rotation moment. In Fig. 4, $a$ the segment $a-R_{k-1}^{t_{0}+\tau^{\prime}}$ represents the fact of rotation moment $M_{e}$ stability in case of friction clutches operation. However there is another way to control the engine possible, in particular, acceleratedly (dynamically, immediately). Fig. $4, b$ highlights these accelerated transition moments of the engine's work that belong to the line $N_{e}=N_{e}^{+}\left(\omega_{e}\right)-$ a set of external modes and can be implemented during the operation of friction clutches. In this case for the chosen duration of the gears shift the currant mode of the engine operation moves along the line $R_{k}^{t_{A}}-R_{k}^{t_{0}}-a-R_{k-1}^{t_{0}+\tau "}-b-R_{k-1}^{N}-R_{k-1}^{t_{B}}$ respectively. We observe some changes in the designation of the upper symbol of $R_{k-1}^{t_{0}+\tau}$ mode - the Fig. 4, a contains $\tau^{\prime}$ instead of $\tau$, whereas Fig. 4, $b-\tau$ ", respectively.

Let us name the first mode of engine control M-control (according to indication $M=$ const), the second - N-control (or dynamic control - according to indication of complete belonging to the external modes of engine operation $\left.N_{e}=N_{e}^{+}\left(\omega_{e}\right)\right)$.

It is worth mentioning that it is possible to keep to this set motion program during the whole time of the shift only under certain conditions. The speed of skidding of friction clutches $\Phi_{k}$ and $\Phi_{k-1}$ (Fig. 3) are defined by the following formulas accordingly

$$
\begin{gathered}
\omega_{s k}=\omega_{e}-\omega_{4}=\omega_{e}-\omega_{a}, \\
\omega_{s(k-1)}=\omega_{e}-\omega_{1}=\omega_{e}-\frac{z_{4}}{z_{3}} \frac{z_{2}}{z_{1}} \omega_{4}=\omega_{e}-\frac{\omega_{a}}{u_{k-1}},
\end{gathered}
$$

where $\omega_{1}, \omega_{4}$ - the speed of gears rotation with the number of teeth $z_{1}, z_{4} ; z_{2}$ and $z_{3}$ - the number of gearwheel teeth of the countershaft (the velocity of rotation $-\omega_{23}$ ).

We consider that $M_{a}>0$ (i.e. we do not mean the deceleration of the vehicle by the engine) consequently the following conditions should be true

$$
\omega_{e}>0, \omega_{a}>0, \omega_{s k}=\omega_{e}-\omega_{a} \geq 0,
$$

(if $\omega_{s k}=\omega_{e}-\omega_{a}<0$ the condition the condition $\omega_{s(k-1)}=\omega_{e}-\omega_{a} / u_{k-1}<0 \quad\left(u_{k-1}<1\right.$ could be also true, which means that the vehicle is decelerated by the engine). The value

$$
\omega_{s(k-1)}=\omega_{e}-\omega_{a} / u_{k-1}\left(u_{k-1}<1\right)
$$

in general for both operations can be only negative. Thus the direct transmission of rotation moment is possible only for friction clutch of the higher transmission

$$
M_{k}^{\phi} \omega_{s k}=M_{k}^{\phi}\left(\omega_{e}-\frac{\omega_{a}}{u_{k}}\right) \geq 0, M_{k-1}^{\phi} \omega_{s(k-1)}=M_{k-1}^{\phi}\left(\omega_{e}-\frac{\omega_{a}}{u_{k-1}}\right) \leq 0 .
$$


Then, the reverse transition of the rotation moment through the friction clutch of lower gear will result in the deviation from a set motion program (see Fig. 5, the program $\omega_{a}=\omega_{a}^{*}(t)$ on the lower diagram). It means that the deceleration during friction clutches skidding will be more intensive. Then the factual duration of the switch (synchronization) will be somewhat smaller than it was planned $\left(t_{0}+\tau\right)$. Scilicet at the $M$-control the factual duration will be $t_{0}+\tau^{\prime}$ while at $N$-control $t_{0}+\tau^{\prime \prime}$ respectively. In general the condition $\tau>\tau^{\prime}>\tau^{\prime \prime}$ is satisfied.

Consequently, for both modes of the engine control at a time section $t_{0}$ to $t_{0}+\tau^{\prime}$ or $t_{0}+\tau^{\prime \prime}$ the program $v=V(t)$ of automobile's motion receives revisions (see Fig. 2 - the curves $v=V_{M}(t)$ and $\left.v=V_{N}(t)\right)$. Considering the inviolability of the selected motion program strategy it is required to take steps to "restore" the program $v=V(t)$. To achieve this after the friction clutches skidding is over, starting with the moment $t_{0}+\tau^{\prime}$ for $M$-control and the moment $t_{0}+\tau^{\prime \prime}$ for $N$-control, the engine operation mode should immediately go to the line $N_{e}=N_{e}^{+}\left(\omega_{e}\right)$ and belong to it to a certain moment, respectively, $t_{S}^{M}$ and $t_{S}^{N}$ when negative consequences of such control are eliminated (points $R_{k-1}^{M}$ and $R_{k-1}^{N}$ ). Contrary to $M$-control, at $N$-control we observe a slight deviation from the program $V(t)$ (the curve $V_{N}(t)$ in Fig. 2). The end of the deviation from the program $V(t)$ will take place earlier, and the duration of its operation in the modes of the line $N_{e}=N_{e}^{+}\left(\omega_{e}\right)$ will end perceptibly earlier (the point $R_{k-1}^{N}$ ). Thus, for the points $R_{k-1}^{N}$ and $R_{k-1}^{M}$, respectively, the following is true $t_{S}^{N}<t_{S}^{M}$. Thus the application of dynamic control insignificantly distorts the motion program compared with the non-dynamic one.

The reverse transition of the rotation moment through the friction clutches of the lower gear leads, among all mentioned above, to the correction of the factual moment of synchronization completion of friction clutches' leading and led elements. For both modes of engine control it will occur earlier than the calculated moment $t_{0}+\tau$. This moment should be treated as a point that belong to the law of friction elements $\Phi_{k}$ and $\Phi_{k-1}$ operation. For the program (3) of friction clutches shift remains unchangeable under any modes of engine control.

This condition should not be neglected. It is to be recalled that the system of automated control of gear shift should secure the smooth (without thrusts and shocks) switch of the friction elements. Fig. 5 demonstrates that at the moment of factual synchronization completion the value of rotation moments of friction clutches $\Phi_{k}$ and $\Phi_{k-1}$ fail to satisfy the condition of the shift process: $M_{k}^{\phi}=0$ and $M_{k-1}^{\phi}=M_{a}$. Then at this moment the system of automated control of friction elements should ensure the a sudden turnoff of friction clutch $\Phi_{k}$ and a complete turn-on of friction clutch $\Phi_{k-1}$. Otherwise the gear shift will be uneven with a thrust.

Considering all mentioned above it is reasonable to differentiate between the duration of the friction clutches control $\tau$ and factual duration of synchronization $\tau^{\prime}\left(\tau^{\prime \prime}\right)$. Objectively it is possible to work out such laws of friction clutches control (minimal values $\tau_{\text {min }}$ ), under which the condition $t_{0}+\tau=t_{0}+\tau_{\text {min }}$ is fulfilled. According to the characteristic of the smoothness of shifts these laws could be considered optimal.

\section{Effectiveness of Gear Shift Laws}

It is possible to substantiate the appropriateness of engine control mode selection in the process of gear shift when the moments of it start $t_{i}=t_{0}$ and time of friction clutches operation $\tau_{j}=\tau$ are set when the expenditure of fuel $Q_{A B}\left(t_{i}, \tau_{j}\right)$ is kept in mind in the process of representation of a set fragment of automobile's motion program $v=V(t)$. To define the expenditure of fuel the following formulas are applied 


$$
\begin{gathered}
Q_{A B}^{M}\left(t_{0}, \tau\right)=\int_{t_{A}}^{t_{0}} Q_{t}\left(M_{e k}(t), \omega_{e k}(t)\right) d t+\int_{t_{0}}^{t_{0}+\tau^{\prime}} Q_{t}\left(M_{e k(k-1)}(t)=\text { const, } \omega_{e}(t)\right) d t+ \\
+\int_{t_{0}+\tau^{\prime}}^{t_{S}} Q_{t}\left(M_{e(k-1)}^{+}(t), \omega_{e(k-1)}(t)\right) d t+\int_{t_{S}}^{t_{B}} Q_{t}\left(M_{e(k-1)}(t), \omega_{e(k-1)}(t)\right) d t \\
Q_{A B}^{N}\left(t_{0}, \tau\right)=\int_{t_{A}}^{t_{0}} Q_{t}\left(M_{e k}(t), \omega_{e k}(t)\right) d t+\int_{t_{0}}^{t_{0}+\tau^{\prime \prime}} Q_{t}\left(M_{e k(k-1)}^{+}(t), \omega_{e}(t)\right) d t+ \\
+\int_{t_{0}+\tau^{\prime \prime}}^{t_{S}} Q_{t}\left(M_{e(k-1)}^{+}(t), \omega_{e(k-1)}(t)\right) d t+\int_{t_{S}}^{t_{B}} Q_{t}\left(M_{e(k-1)}(t), \omega_{e(k-1)}(t)\right) d t
\end{gathered}
$$
shift.

Formulas (10) and (11) are applicable in cases of $M$ - and $N$-control of the engine (see Fig. 4).

Fig. 6 represents fuel automobile's characteristic in deceleration mode with the simultaneous gear

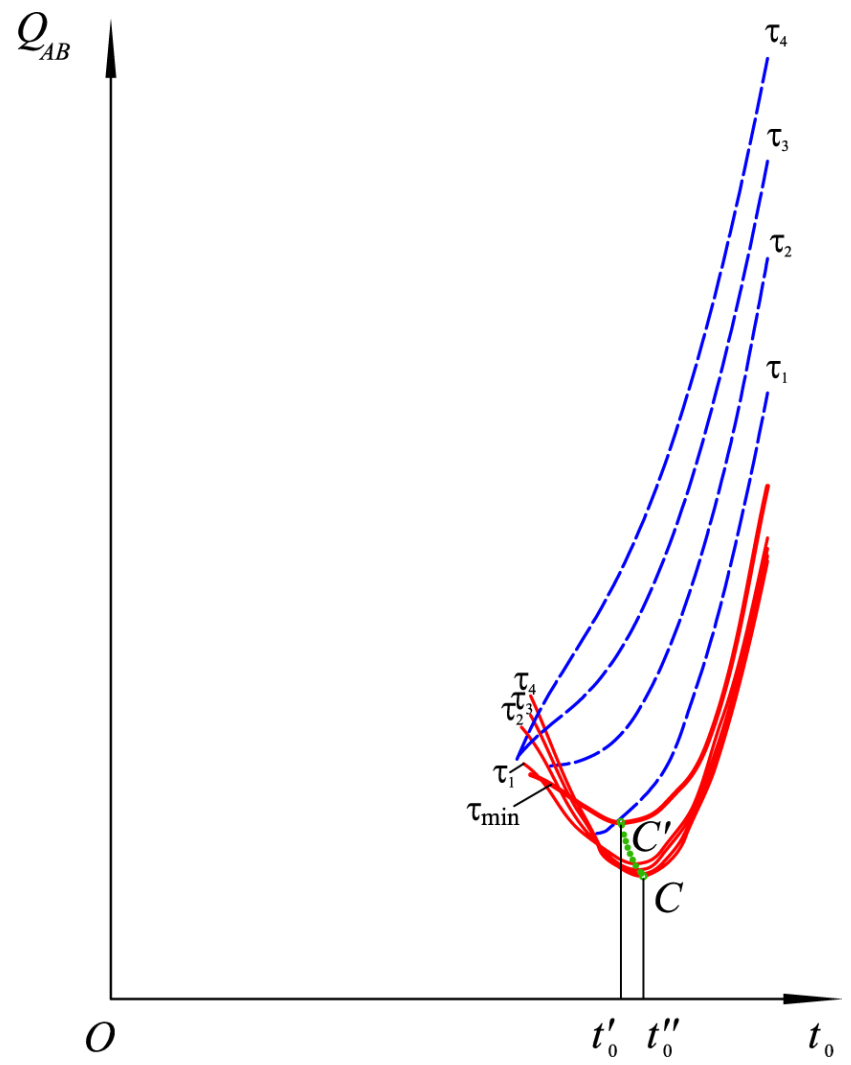

Fig. 6. Automobile's fuel characteristics

This implies that the expenditure of fuel perceptibly depends on the choice of the moment $t_{0}$ of gear shift start. The loss of fuel is considerable determined by the time of friction clutches skidding $\tau_{j}$ ( $j=\overline{1 ; 4}, \tau_{j}<\tau_{j+1}$ ), especially when the $M$-control mode of engine operation is not accelerated (boosted) (hatches in Fig. 6). Obviously, that jointly $N$-control of the gear shift (firm lines in Fig. 6) are always more energy saving in comparison to the $M$-control. Notably that unaccelerated $M$-control can be intensified decreasing the time $\tau$ of friction clutches skidding. It will facilitate saving of fuel.

At any fixed value of duration $\tau_{j}$ of gear shift $N$-control boosted process the optimal moment $t_{0}$ of shift start can be found as a local minimum of relating correspondence $Q_{A B}=Q_{A B}\left(t_{0} ; \tau_{j}=\right.$ const $)$. Such 
extreme points jointly form a certain line $C C^{\prime}$ of optima on a set of all possible values $\tau_{j}$ on which the condition $\partial Q_{A B}\left(t_{0} ; \tau_{j}\right) / \partial t_{0}=0$ of local extremum is satisfied. This line makes it possible to identified those energy effective engine control modes the moment of which realization is the most appropriate for gear shift. But if the value $\tau$ is not defined in any way in advance it is necessary to seek for its smallest value at the beginning of $\left(t_{0}{ }_{0}, t{ }^{\prime}{ }_{0}\right)$ set, then let it rise to a certain value $\tau_{4}$ in proportion to the increase of $t_{0}$. In case of unaccelerated $M$-control the priority should be given the fuel saving moments of the shift that occur earlier. Later moments of the shift are too energy ineffective.

Consequently, the boosting (dynamic character) of gear shift has irrefutable advantages of fuel expenditure in case of automobile deceleration program realization, as well as in the process of its acceleration [13]. Irrespective of the fact that the friction clutches shift mode with an interval $\tau_{\min }$ is less effective than boosted modes which are longer its advantage lies in the fact that the duration of friction clutches control and factual duration of synchronization become equal: $t_{0}+\tau_{\min }=t_{0}+\tau^{\prime \prime}$. It considerably simplifies the algorithm of friction clutches control, since it enables to avoid jerky (with a thrust) gear turn-on.

In the theory of automobile automated transmission control the effectiveness of transition processes are usually estimated according to the loss (level, stage of dispersion) of energy in the period of gear shift. The question arises, whether the principle of stability of the chosen by a driver mode of automobile's motion contradicts with this classical criterion.

The amount of energy brought up to the gearbox in the process of its shift can be calculated according to the formula

$$
W_{e}=\int_{t_{0}}^{t_{0}+\tau}\left(M_{e}-I_{e} \frac{d \omega_{e}}{d t}\right) \omega_{e} d t=\int_{t_{0}}^{t_{0}+\tau}\left(M_{k}^{\phi}+M_{k+1}^{\phi}\right) \omega_{e} d t=\int_{t_{0}}^{t_{0}+\tau} M_{k(k+1)}^{\phi} \omega_{e} d t=\int_{t_{0}}^{t_{0}+\tau}(a t+b) \omega_{e} d t,
$$

and the amount of energy that leaves the gearbox during the same lapse of time - according to the formula

$$
W_{a}=\int_{t_{0}}^{t_{0}+\tau} M_{a} \omega_{a} d t=\frac{r_{\mathrm{K}} u_{0}}{\eta_{\mathrm{Tp}}} \int_{t_{0}}^{t_{0}+\tau}\left(G_{\mathrm{a}} \psi+k_{\Pi} F v^{2}(t)+m_{\mathrm{a}} \delta \frac{\mathrm{d} v(t)}{\mathrm{d} t}\right) \omega_{a} d t
$$

In this case the following formula

$$
\begin{gathered}
W_{s}=W_{e}-W_{a}=\int_{t_{0}}^{t_{0}^{+\tau}}\left(\left(M_{e}-I_{e} \frac{d \omega_{e}}{d t}\right) \omega_{e}-M_{a} \omega_{a}\right) d t= \\
=\int_{t_{0}}^{t_{0}+\tau}\left((a t+b) \omega_{e}-\frac{r_{\mathrm{K}} u_{0}}{\eta_{\text {тр }}}\left(G_{\mathrm{a}} \psi+k_{\Pi} F v^{2}(t)+m_{\mathrm{a}} \delta \frac{\mathrm{d} v(t)}{\mathrm{d} t}\right) \omega_{a}\right) d t
\end{gathered}
$$

defines the amount of energy dispersed by the friction clutches in the form of heat.

Nevertheless the deviations from the desired motion program is unavoidable: it is caused by technical limitations in the system of automated gear shift. The level of local deviations from the determined automobile's motion program for a specified moment $t_{0}$ for the start and factual duration of the shift can be estimated by the following formula

$$
\Delta S=\int_{t_{0}}^{t_{V}^{*}} V(t) d t-\int_{t_{0}}^{t_{V}^{*}} V_{*}(t) d t
$$

The character of energy loss dependence in the friction clutches $W_{S}$ from the choice of gear shift moment $t_{0}$ and the duration of the friction clutches shift $\tau$ calculated by the formula (14) is represented in Fig. 7 whereas the level $\Delta S$ (see (15)) of automobile's motion program deviations from a desired (specified) as a consequence of gear shift system operation is illustrated in Fig. 8. As it was stated above (see Fig. 6), the hatches corresponds to the $M$-control, the firm line - for the $N$-control. 


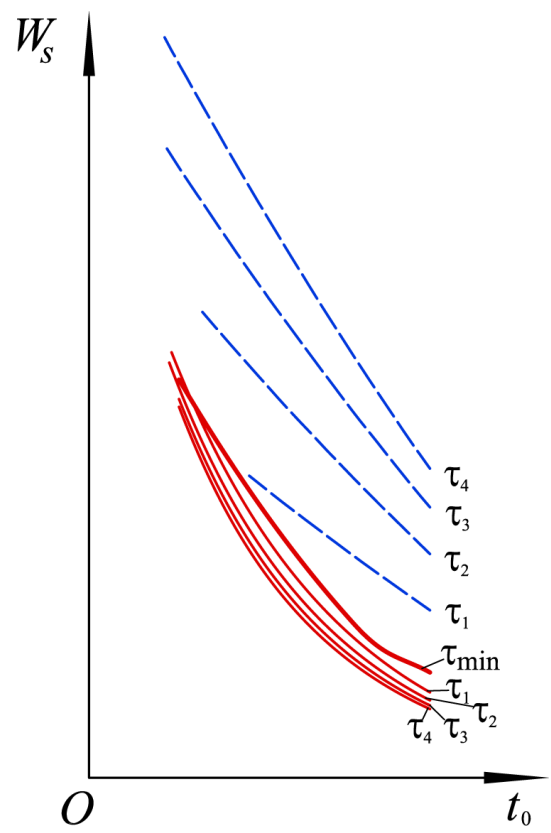

Fig. 7. Characteristic of energy losses in friction clutches

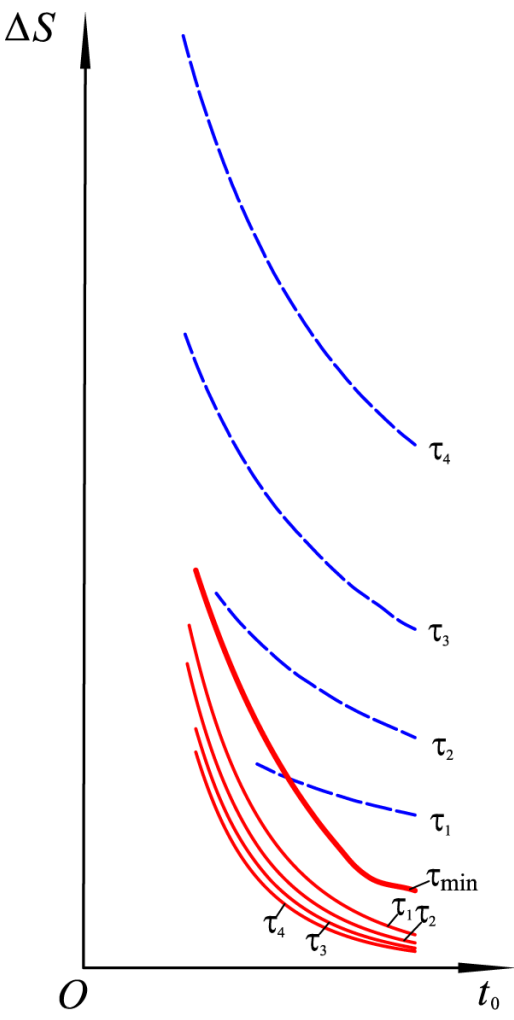

Fig. 8. Characteristics of deviations from the specifies program of automobile's motion

Analyzing the impact made by the start of gear shift process and the duration of friction clutches operation on heat losses of energy $W_{S}$ (see Fig. 7) and on the deviations $\Delta S$ from a real automobile's motion program from the specified one (see Fig. 8) it is easy to observe that the later shifts are more advantageous. However the accelerated (boosted) shifts jointly are more efficient than non-accelerated.

\section{Conclusions}

Notwithstanding the drivers decision in the choice of the automobile's motion mode and in spite of the road conditions and circumstances the system of automated control "engine - transmission" is to be guided by a sheer dynamic laws of functioning. The dynamic laws of "engine - transmission" system functioning facilitate among others the preservation of energy (minimization of the loss of fuel). Thus the contradictions between the requirements of the energy saving and dynamics are absolutely annihilated. The suggested conclusion relates both to the automobile's acceleration regime studies previously and the deceleration regime discussed in this article.

The participation of the engine in the process of gear change is the realization of the principle of active velocity synchronization of specific transmission elements on the adjacent gears in the process of their shift. Herewith the transfer of mechanical energy through transmission is carried out by a continuous flow. The realization of the dynamic principles of automation lead to the decrease of mechanical energy transformed to the heat in the process of gear shift elements skidding (for example, the friction clutches). Because of this there is the possibility to increase the durability of the elements of the shift or to put forward less specified requirements for their operations in the process of transmission design.

The described algorithm of automobile's transmission control lay the ground for the development of motivated regulations concerning the choice of the gear shift moments even in the case when the automobile is operated manually.

The achieved results are rather general, although a considerable simplification have been introduced into the model of an automobile. In particular, schematically very simple gearbox actually completely 
represents the principles of operation of all-type mechanic stage transmission. The process of gear shift is so transient that the linear representation of "engine-transmission" system operation modes is absolutely natural and is construed as such that cannot distort the concept of "engine-transmission" system functioning efficiency.

\section{References}

[1] B. F. Brender, C. J. Canever, I. J. Monti, and J. R. Johnson, "Laboratory Simulation, Mark II-GT Powertrain." SAE International, 1967.

[2] H. J. Förster, H. Gaus, "Die Steuerung Automatischer Getriebe - ein Sonderfall der Kompaktbauweise in der Ölhydraulik" ["The control of automatic transmissions - a special case of compact design in oil hydraulics"], Automobil-Industrie [Automotive Industry], no. 4, pp. 61-73, 1971. [in German].

[3] "AT-Service: Toyota-Automatik-Getriebe A40. Aufbau und Wirkungsweise; Pflege- und Einstellarbeiten; Prüf- und Reparaturhinweise" ["AT-Service: Toyota automatic gearbox A40. Structure and mode of operation; Maintenance and adjustment work; Inspection and repair instructions"], Autotechnik [Autotechnik], no. 24, pp. 25-35, 1975. [in German].

[4] R. S. Holmes, R. R. Smyth, and D. Speranza, "Automated Mechanical Transmission Controls", SAE Technical Paper Series, no. 831776, pp. 1-9, 1983.

[5] M. Schwab, "Electronic Control of a 4-Speed Automatic Transmission with Lock-Up Clutch", SAE Technical Paper Series, no. 840448, pp. 85-93, 1984.

[6] G. Koralewski, "Metodyka wyznaczania optymalnych momentów przełączania biegów przekładni hydromechanicznej w czasie rozpędzania samochodu" ["Methodology for determining the optimal transmission torque of the hydromechanical transmission gear during the acceleration of the car"], Folia Societatis Lublinensis, vol. 5, no. 1, pp. 5-17, 1996. [in Polish].

[7] P. N. Hashchuk, Energeticheskaia effektivnost avtomobilia [Vehicle energy efficiency]. Lviv, Ukraine: Svit Publ., 1992. [in Russian].

[8] E. G. Dini, "Sulla regolazione delle trasmissioni automatiche per autoveicoli" ["On the regulation of automatic transmissions for motor vehicles"], Giornale ed atti della "Associazione tecnica dell'automobile" [Journal and Acts of the "Automobile Technical Association"], no. 12, pp. 690-707, 1966. [in Italian].

[9] P. M. Hashchuk, and R. A. Pelo, "Vzaiemozumovlenist struktury riadiv peredatnykh vidnoshen ta optymalnykh zakoniv peremykannia stupenevoi transmisii avtomobilia" ["Interdependence of the structure of the series of transmission ratios and the optimal laws of switching the stage transmission of the car"], Visnyk Natsionalnoho universytetu "Lvivska politekhnika": Optymizatsiia vyrobnychykh protsesiv i tekhnichnyi kontrol u mashynobuduvanni ta pryladobuduvanni [Bulletin of Lviv Polytechnic National University: Optimization of production processes and technical control in mechanical engineering and instrument making], no. 515, pp. 74-80, 2004. [in Ukrainian].

[10] P. M. Hashchuk, and R. A. Pelo, "Osoblyvosti optymalnoho peremykannia peredach u bahatostupenevii transmisii avtomobilia" ["Features of the optimum gearshift in the multi-stage car transmission"], Visnyk Skhidnoukrainskoho natsionalnoho universytetu imeni Volodymyra Dalia [Bulletin of the Volodymyr Dahl East Ukrainian National University], no. 7 (101), pp. 45-48, 2006. [in Ukrainian].

[11] R. A. Pelo, "Obgruntuvannia deiakykh vlastyvostei avtomata keruvannia transmisiieiu avtomobilia" ["Substantiation of some properties of the car control automaton"], Proektuvannia, vyrobnytstvo ta ekspluatatsiia avtotransportnykh zasobiv i poizdiv [Design, manufacture and operation of motor vehicles and trains], vol. 9, pp. 94-98, 2006. [in Ukrainian].

[12] P. M. Hashchuk, and R. A. Pelo, "Obgruntuvannia vyboru prohramy peremykan v mekhanichnii transmisii avtomobilia pry realizatsii zadanoi prohramy rukhu" ["Justification of the choice of the program of switching in the mechanical transmission of the car in the implementation of a given program of motion"], Avtomatyzatsiia vyrobnychykh protsesiv u mashynobuduvanni ta pryladobuduvanni [Industrial Process Automation in Engineering and Instrumentation], vol. 41, pp. 73-80, 2007. [in Ukrainian].

[13] P. M. Hashchuk, and R. A. Pelo, "Analiz perekhidnoho protsesu pry avtomatyzovanomu peremykanni stupeniv transmisii avtomobilia" ["Analysis of the transition process at the automated switching stages of the car transmission"], Visnyk Natsionalnoho transportnoho universytetu [Bulletin of the National Transport University], vol. 18, pp. 32-41, 2009. [in Ukrainian]. 